\title{
Interrelation and Spillover Effects between Stocks and Bonds: Cross-Market and Cross-Asset Evidence
}

\author{
David G McMillan \\ Division of Accounting and Finance \\ University of Stirling \\ August 2019 \\ Revised February 2020 \\ Second Revision April 2020
}

\begin{abstract}
Purpose:

This paper examines the behaviour, both contemporaneous and causal, of stock and bond markets across four major international countries.
\end{abstract}

Design/Methodology/Approach:

We generate volatility and correlations using the realised volatility approach and implement a general VAR approach to examine causality and spillovers.

Findings:

While results confirm that same asset-cross country return correlations and spillovers increase over time, the same in not true with variance and covariance behaviour. Volatility spillovers across countries exhibit a substantial amount of time-variation, however, there is no evidence of trending in any direction. Equally, cross asset-same country correlations exhibit both negative and positive values. Further, we report an inverse relation between same asset-cross country return correlations and cross asset-same country return correlations i.e., the stock return correlation across countries increases at the same time the stock and bond return correlation within each country declines. Moreover, results show that the stock and bond return correlations exhibit commonality across countries. Results also demonstrate that stock returns lead movement in bond returns, while US stock and bond returns have predictive power other country stock and bond returns. In terms of the markets analysed, Japan exhibit a distinct nature compared with those of Germany, the UK and the US.

\section{Originality}

The results presented here provide a detailed characterisation of how assets interact both with each other and cross countries and should be of interest to portfolio managers, policy-makers and those interested in modelling cross market behaviour. Notably, we reveal key differences between the behaviour of stocks and bonds and across different countries.

Keywords: Stocks, Bonds, Returns, Volatility, Correlation, Causality, VAR, Spillovers JEL Codes: C22, G12

Address for Correspondence: Professor David McMillan, Accounting and Finance Division, University of Stirling, FK9 4LA

Telephone: $+44(0) 1786-467309$

Fax: +44(0)1786-467308

E-mail: david.mcmillan@stir.ac.uk 
Acknowledgements: The author gratefully acknowledges the helpful comments of two anonymous referees and the editor that have enabled to paper to be revised and improved.

\section{Introduction.}

Understanding the nature of the interactions between stocks and bonds both across countries and across assets is important for investors, academics and economic policy-makers. Notably, while investors are concerned about the implications for portfolio building, academics and policy-makers are keen to understand the links and spillover effects between markets and assets. Together, these effects can enhance our knowledge of the transmission mechanism and flow of information, which can drive market behaviour and have implications for the wider economy. The movement in correlations provides information about how investors view future market and economic risk as they move between safer and riskier assets. Spillovers, where the information in one market may impact a second market, can provide predictive content for the subsequent movement in asset prices. Such information can allow investors to improve portfolio performance and for policy-makers to take corrective action in the event of the transmission of negative shocks.

The spillover literature largely began with Engle et al (1990), who identify intra (heatwaves) and inter (meteor showers) market effects using the GARCH methodology. Although, prior to this, Eun and Shin (1989) consider a VAR approach. Nonetheless, the GARCH approach led to a raft of subsequent research examining the presence of mean and variance spillovers across a range of markets. Examples include, Hamao et al (1990), Liu and Pan (1997) and Li (2007) who all consider spillover effects in volatility (and mean) across a range of stock markets. While much of this early research was motivated by the stock market crash of 1987, the financial crisis that began in 2007 provides fresh impetus to this work. Examples include, Kenourgios and Dimitriou (2015), Mensi et al (2016) and Bala and Takimoto (2017). While the GARCH approach has predominately been used in examining spillover effects, as noted, it is not the only approach. McMillan et al (2010) use the realised 
variance approach to examine volatility spillovers between Euro exchange rate series. Diebold and Yilmaz $(2009,2012)$ introduce the spillover index methodology, which utilises a VAR framework to examine the time-varying nature of spillovers and provides an overall measure of spillover strength.

Examining the correlation across markets for the same asset and across assets occupies a large area of research given its importance in portfolio building and diversification. The literature has reached a broad consensus that correlations for the same asset have trended upwards over time due to increased financial integration (although a debate surrounds the potential for contagion effects to impact correlation behaviour, see for example, Forbes and Rigobon, 2002; Bekaert et al, 2005; Dimitriou et al, 2013). However, a much larger debate exists about the nature of correlations across asset classes. With reference to the correlation between stocks and bonds, there is evidence of significant time-variation and cycling between periods of both positive and negative correlations. For example, the expectation of a positive correlation between stock and bond returns is identified by, among others, Barsky (1989), Shiller and Beltratti (1992) and Campbell and Ammer (1993). However, a negative correlation that may arise during times of economic stress and result from a flight-to-safety effect, is highlighted by, for example, Gulko (2002), Connolly et al. (2005) and Andersson et al (2008). Baur and Lucey (2009) also consider the role of contagion as well as flight-to-safety effects in the nature of the stock and bond relation, while Kim et al (2006) argue that segmentation between of bond and stock markets leads to a falling correlation. McMillan (2019) also notes changing correlations between assets linked to economic conditions. Both Connolly et al (2007) and Baur (2010) examine the potential interaction for same asset and cross-asset correlation. Notably, the latter argues that higher risk leads to rising same asset correlation through a contagion effect and falling cross-asset correlation due to flight-to-safety.

Understanding the interaction between stock and bond returns is a key ingredient in the 
construction of portfolios. Stocks and bonds still form the majority of asset holdings within portfolios and the time-varying nature of the correlation has implications for diversification benefits. Moreover, any temporal interaction between the two assets will also benefit investors in timing changes in asset allocation. Tolikas (2018) examines the lead and lag relation between stocks and bonds and argues that while the former exhibits no such leading role for investment grade bonds, it does so for high yield (and higher risk) bonds. Extending this line of research further, spillovers in the correlation between stocks and bonds across markets may indicate that investor risk appetites are changing globally, as switching between stocks and bonds in one market, affects similar holdings in another market. ${ }^{1}$

A key issue that arises is how to construct both volatility and correlation series and examine their interaction. This arises as neither of these series are observable. A common approach to generating volatility series is the GARCH methodology (Engle, 1982; Bollerslev, 1986), although using squared returns is not uncommon (see the general discussion in Pagan and Schwert, 1990, and as an example of its use, McMillan et al, 2000). For the correlation, an obvious approach is to use an extension of the GARCH model that allows for the joint modelling of asset returns and their covariance. Examples of this include, Baur and Lucey (2010) who use a multivariate-GARCH model and Colacito et al (2009), who use an extension of the DCC model of Engle (2002). An alternative, simpler, approach is to use rolling windows for the correlation between two series. Fan and Mitchell (2017) use a 1-year and 5-year rolling window to illustrate the nature of time-variation, while Rankin and Shah Idil (2014) consider a variety of window lengths. A more recent approach builds upon the realised volatility literature (see, McAleer and Medeiros, 2008 for a general review). Using this approach, we can

\footnotetext{
${ }^{1}$ An examination of the interaction between stocks and bonds can also be considered through the bond beta, which examines the riskiness of bonds and is constructed as the covariance between stock and bond returns divided by the variance of stock returns (i.e., the equivalent of a CAPM beta). This measure, thus, captures systematic risk in bonds and we can examine whether such risk transmits across markets. Existing work examining the behaviour of the bond beta includes Viceira (2012), Campbell et al (2017) and Aslanidis et al (2019).
} 
construct realised measures for both volatility and covariance and thus construct the realised correlation. This approach is taken by Aslanidis and Christiansen (2012) for the stock and bond correlation. Evans and McMillan (2009) consider both a GARCH and realised correlation approach to examine co-movements across a wide range of international stock markets.

This paper seeks to examine the interactions between stock and bond markets across four major countries and financial centres (Germany, Japan, the UK and the US) and tie together different literatures that consider correlations and causality (spillovers) across assets and markets. Specifically, in this paper we consider the spillover and causality effects between international stock and bond markets, including both within and across countries. The paper also considers the time-varying nature of correlations both for the same asset across countries and across assets. Thus, the paper seeks to provide a complete characterisation of the nature of the interrelations between stocks and bonds across major international markets. The results in this paper should be of interest to investors, academic and policy-makers, as they will aid our understanding of how assets interact with each other and across markets. We focus on monthly observed interactions as this is relevant for both portfolio managers and policy-makers for whom temporary high-frequency movements will carry less information in comparison to more persistent lower frequency changes. This will improve our knowledge of how information flows across assets and markets allowing investors to improve portfolio building and policymakers to engage in any necessary corrective action.

\section{Empirical Methodology.}

The empirical method used in this study focusses on the vector autoregression (VAR; Sims, 1980) and two related techniques, Granger causality tests and the spillover index of Diebold and Yilmaz $(2009,2012)$. The general $k$-variable, $p$-lagged VAR model is given by:

$$
x_{t}=\sum_{i=1}^{p} \varphi_{i} x_{t-i}+\varepsilon t
$$


where $x_{t}$ represents the vector of $k$ endogenous variables, while $\varphi$ is a $k x k$ matrix of parameters for each time lag, $p$, and $\varepsilon_{t} \sim(0, \Sigma)$ is a vector of disturbances that are assumed to be independently and identically distributed over time. To determine the lag length of the VAR, we use the AIC, which should ensure white noise residuals.

To examine Granger (1969) causality, we can specify a two-variable VAR as such:

$$
\begin{aligned}
& x_{1 t}=P(L) x_{1 t}+Q(L) x_{2, t}+\varepsilon_{1, t} \\
& x_{2 t}=R(L) x_{1 t}+S(L) x_{2, t}+\varepsilon_{2, t}
\end{aligned}
$$

where $P(L), Q(L), R(L)$ and $S(L)$ are one-sided lag polynomials of order $p, q, r$ and $s$. The regression errors are assumed to be mutually independent and white noise. The null hypothesis that $x_{2}$ does not Granger-cause $x_{1}$ is rejected if the coefficients on the elements in $Q(L)$ are jointly significantly different from zero. Bi-directional causality exits if the coefficients in both $Q(L)$ and $R(L)$ are jointly significantly different from zero.

To examine the nature of spillovers between series, we use the approach of Diebold and Yilmaz $(2009,2012)$ and, in particular, the generalised VAR framework of Koop et al (1996) and Pesaran and Shin (1998) implemented in Diebold and Yilmaz (2012). This approach allows the variance decomposition to be invariant to the ordering of the VAR variables.

Assuming covariance stationarity, equation (1) can be rewritten as an infinite moving average model, as such:

$$
x_{t}=\sum_{i=0^{\infty}} A_{i} \varepsilon_{t-i}+\varepsilon t
$$

The parameter matrices, $\mathrm{A}_{\mathrm{i}}$, are recursively defined as follows: $A_{1}=\varphi_{1} A_{i-1}+\varphi_{2} A_{i-2}+\ldots+\varphi_{p}$ $A_{i-p}$ and with $A_{0}$ a $k x k$ identity matrix. The variance decompositions allow the fraction of the $H$-step ahead error variance in forecasting $x_{i}$ owing to shocks arising from $x_{j}$, where $i \neq j$ to be calculated. The H-step-ahead forecast error variance decomposition is given by:

$$
\theta_{i j}(H)=\frac{\sigma_{i i}^{-1} \sum_{h=0}^{H-1}\left(e_{j}^{\prime} A_{h} \Sigma e_{i}\right)^{2}}{\sum_{h=0}^{H-1}\left(e_{j}^{\prime} A_{h} \Sigma A_{h}^{\prime} e_{j}\right)}
$$


where $\Sigma$ is the (estimated) variance matrix of the error vector $\varepsilon, \sigma_{i i}$ the (estimated) standard deviation of the error term for variable $i$, and $e_{i}$ is the selection vector with one as the $i t h$ element and zero otherwise.

Each element of the variance decomposition matrix is then normalised by the sum of the elements of each row of the decomposition as such:

$$
\tilde{\theta}_{i j}^{g}(H)=\frac{\theta_{i j}^{g}(H)}{\sum_{j=1}^{k} \theta_{i j}^{g}(H)}
$$

This is to ensure that the own and cross-variable variance contribution sum to one under the generalised decomposition with $\sum_{j-1}^{k} \tilde{\theta}_{i j}^{g}(H)=1$ and $\sum_{i, j-1}^{k} \tilde{\theta}_{i j}^{g}(H)=k$ by construction. The total spillover index is then defined as:

$$
\operatorname{TS}^{g}(H)=\frac{\sum_{i, j=1, i \neq j}^{k} \tilde{\theta}_{i j}^{g}(H)}{\sum_{j=1}^{k} \tilde{\theta}_{i j}^{g}(H)} x 100 .^{2}
$$

A key issue in the analysis is to calculate the variance and covariance across series, as such variables are typically unobserved. One common approach is the GARCH methodology, including the DCC model, to obtain fitted values for the variance and correlation. However, a drawback of this general approach is that there is no preferred model specification and the resulting series are subject to estimation error. To calculate the variance and covariance/correlation, we use the realised volatility approach, which utilises higher frequency data to compute the lower frequency variable of interest. This approach has the advantage of reducing noise within the constructed series, allowing for more accurate estimation, while the series can be treated as observed and modelled directly. The realised volatility approach largely began with Andersen and Bollerslev (1998), although its use pre-dates that, with French et al (1987) and Schwert (1989) both using daily data to construct monthly volatility. Since the work

\footnotetext{
${ }^{2}$ Directional spillovers can also be calculated but we do not consider them here.
} 
by Andersen and Bollerslev (1998), the use of higher frequency data in constructing lower frequency variables has become popular (see, for example, Andersen et al, 2003; McAleer and Medeiros, 2008, Nakajima, 2019). Realised volatility is constructed by summing over the lower frequency, the squared returns of the higher frequency data. Thus, we obtain daily returns data, which is squared and summed over the month, which is the frequency of interest. Likewise, the realised covariance between two assets, e.g., stock and bond returns, is obtained as the product of the two asset returns. Respectively, two series are generated as:

$$
\begin{aligned}
& \sigma_{i, t}^{2}=\sum_{d=1}^{M} r_{i, d, t}^{2} \\
& \sigma_{s b, t}=\sum_{d=1}^{M}\left(r_{s, d, t}^{2} r_{b, t, d}^{2}\right)
\end{aligned}
$$

where, $d$ refers to the number of days in a month, $M$. The realised variance in equation (7) is constructed for both the stock and bond return series, where $i=s$ and $b$. The realised correlation, $\rho$, series is then constructed as:

$$
\rho_{s b, t}=\sigma_{s b, t} /\left(\sqrt{\sigma_{s, t}^{2}} \sqrt{\sigma_{b, t}^{2}}\right)
$$

\section{Data.}

We obtain stock and bond return data from DataStream for Germany, Japan, the UK and the US. The data is obtained daily over the time period from the first day of 1980 (with the exception of Japanese bond data, which is only available from the first day of 1984) to the last day of May 2018. The index data is based on the Datastream total market index for stocks and the government (Treasury) 10-year constant maturity index for bonds. ${ }^{3}$

As our modelling frequency is monthly, we use the daily data to construct monthly returns, volatility, covariances and correlations. ${ }^{4}$ Monthly returns are calculated as the first-

\footnotetext{
${ }^{3}$ We also consider the daily total return index, but the results are similar to those reported in the text and so do not report them.

${ }^{4}$ The use of a monthly frequency avoids any confounding issues relating to time zones and is a more relevant time horizon for portfolio managers.
} 
difference of the $\log$ of the end of month price. For the volatility and correlation series, as outlined above, we use the realised variation approach. Thus, we obtain squared daily returns and aggregate these over the month to form the volatility series. The monthly realised covariance is the sum over the month of the daily cross-products of the returns series. Monthly correlations are then calculated as the covariance series divided by the product of the two corresponding standard deviations.

Figure 1 presents the return and volatility (square root of the variance) series for the stock and bond data for our four markets. Notable points in the data, for stocks, we can see heightened volatility in the second half of the 1980s, which coincides with the 1987 stock market crash. Higher volatility can also be observed during the dotcom bubble and crash period of the late 1990s and early 2000s and then during the late 2000s following the financial crisis. Noticeably lower volatility can be observed during the early 1980s, early 1990s and the latter 2010s. Across the four markets, we can observe that comparatively Japan exhibits higher volatility across the sample. For the bond market, we generally see higher volatility at the beginning of the sample when interest rates across these markets were typically around the $10 \%$ mark. Subsequently, as interest rates fell, so did bond market volatility, until the financial crisis, whereupon volatility rises before falling back in the latter 2010s. We also present the usual summary statistics in Table 1, which are consistent with established stylised facts.

\section{Correlations Across Assets and Markets}

Before examining the nature of Granger causality and spillovers between the stock and bond series across the four markets, we briefly consider the nature of correlations across markets and assets. Figure 2 presents the same asset correlations between bond and stock returns across the four countries. As noted in the Introduction (e.g., Kim et al, 2006; Connolly et al, 2007; Baur, 2010), previous evidence points to a rising correlation between the same asset across 
international markets. For the interactions between Germany, the UK and the US, we see this trend continuing with the strength of the correlation increasing, particularly from the $1990 \mathrm{~s}$ onwards. Of further interest, we observe the rise in correlation plateauing, and even falling, towards the end of the sample. In contrast, for Japan, the general pattern of the stock and bond return correlations is one fluctuating around a constant mean value.

Figure 3 presents the plots of the stock and bond correlations for the four markets. Across the four markets, we can observe that while the stock and bond return correlations exhibit a relatively high degree of variability, there is a noticeable decrease occurring from the late 1990s and, more obviously, in the early 2000s. Subsequently, the correlation rises in the mid-2000, falls again in the latter 2000s and then begins to rise around the mid-2010s. The periods of falling correlations are consistent with those of stock market stress, such as the dotcom crash and financial crisis, which supports flight-to-safety behaviour with investors moving out of equities and into bonds. The higher correlations are thus, more associated with normal periods of market behaviour. We can also observe a higher degree of similarity in the correlations for Germany, the UK and the US, while those for Japan indicate different behaviour. For example, the correlation across the stock and bond correlation series between Germany, the UK and the US is over 0.8, while it is less than 0.5 for Japan.

Baur (2010) links the behaviour between the same asset across markets and different assets within the same market. Baur argues that a rise in the correlation of the same asset across international markets is consistent with a fall in the correlation across assets within the same international market. Notably, a period of market stress can lead a contagion effect between international stock markets raising their correlation, while a flight-to-safety effect from stocks to bonds lowers their correlation. This joint contagion and flight-to-safety argument would imply similar behaviour in the stock and bond correlation across markets as investors in each country act in the same way, selling risky stocks and buying safer bonds. From Figure 3, we 
do observe similarity in the stock and bond correlations across the four markets.

To further consider the idea that same asset-cross market and cross asset-same market correlations move in different directions due to the joint contagion and flight-to-safety effect, we can examine their interactions. Table 2 presents the correlation between same asset-cross market and cross asset-same market correlations. For example, any given entry is the correlation between the stock and bond correlation in a country with the stock-stock or bondbond correlation between pairs of countries. From these correlations we can consider the view that a stronger correlation between the same asset (contagion) occurs at the same time as a weaker correlation across assets (flight-to-safety).

The results from this exercise broadly support the above view and again present a distinction between the results that include Japan. Considering the results across each row, we can see whether the stock and bond correlation for each market is related to the same asset correlation across markets. Examining the results for the stock and bond correlation for Germany, the UK and the US, we can see there is a strong negative relation with the corresponding markets bond and stock correlation across other markets. For example, the German stock and bond correlation exhibits a correlation with the German and UK or US bond and stock returns correlation of over (in absolute terms) 0.50 . To be more specific, the correlations between the German stock and bond correlation and the German and UK bond return correlation is -0.629 , while it is -0.541 with the German and UK stock return correlation. Hence, a large negative relation between the same asset-cross market and cross asset-same market correlations. Similarly, strong results are reported for the UK and US stock and bond correlations with international same asset interrelations. These values all support the view that a stronger same asset correlation is consistent with a weaker cross-asset correlation. As before, the results for Japan differ, with very limited evidence of any relation between the same and cross asset correlations. 
The results in this section suggest two important conclusions that are of relevance to investors, policy-makers and those engaged in modelling market behaviour. First, the dynamics of correlations across assets and markets differ when they involve Japan compared to the other major markets. Second, there is an identifiable relation between cross asset-same market and same asset-cross market relations. When the cross asset-same market correlation rises, the same asset-cross market correlation falls.

\section{Empirical Results for Causality and Spillovers.}

\section{Mean and Variance Causality and Spillovers Within Assets}

To examine mean and variance spillovers, a separate VAR model is estimated for the mean and variance series across the four countries. In each case the VAR lag lengths are determined by the AIC and are two and one for the stock and bonds returns respectively, and two and nine for the stock and bond variance series respectively. ${ }^{5}$ In order to present the results in a manageable fashion, Table 3 reports the results of the Granger causality tests for stock market returns and variance using the estimated VARs, for which we report the associated $F$-statistic and $p$-value. Table 4 reports the equivalent values for bond returns and variance.

For stock returns, we identify Granger causality running from UK and US returns to German returns. We also report such causality running from US stock returns to both Japanese and UK stock returns, while evidence of bi-directional causality exists between the UK and Japan (although only at the $10 \%$ significance level). For stock return variance, we see a similar pattern, notably, there is Granger causality running from UK and US variance to German variance. Likewise, there is evidence of causality from UK and US variance to Japanese variance (with 10\% significance level evidence of causality flowing back from Japanese to UK

\footnotetext{
${ }^{5}$ A lag length of nine for bond variance seems particularly long, thus we also consider the BIC for which a lag length of one is identified. Nonetheless, the qualitative nature of the results remains unchanged.
} 
variance). There is also evidence of causality from UK to US variance.

For bond returns (Table 4), we find evidence of bi-directional causality between Germany and Japan and between Japan and the UK. There is also evidence of causality running from US bond returns to both German and Japanese returns. For bond variance, we see bidirectional causality between Germany and Japan, Japan and the UK, Japan and the US and the UK and US.

Across both tables, we can see greater evidence of causality in the bond market compared to the stock market. At the 5\% statistical significance level, there are four and five significant relations for stock returns and variance respectively, while for the bond market the equivalent figures are six and nine. For the stock market, both returns and variance, we observe that predominately the direction of causality is from the UK and US towards Germany and Japan, while for the UK and US, the latter directs causality to the former in returns and receives in variance. Germany and Japan, which predominantly are recipients of causality exhibit no relation with each other. For the bond market, in contrast, Germany and Japan exhibit bidirectional causality and there is greater interaction between Japan, the UK and the US across both returns and variance. These results illustrate the view that major stock market information emanates largely from the US and then the UK, while bond market information arises across each of the major global financial centres.

To further examine the nature of the relations between stock and bond returns and variance across the four markets, we use the spillover index approach of Diebold and Yilmaz (2009, 2012). We only report the time-varying spillover graphs, in Figure 4, while the remaining information (variance decompositions) is available upon request but provides similar information to the Granger causality results. The stock return spillovers graph reveals that spillovers are increasing over the sample period at a relatively steady rate but with a noticeable upward jump for the financial crisis and with a shallower trend afterwards. 
Specifically, the spillover index increased from around $40 \%$ to $50 \%$ from the mid-1990s until 2007, whereupon (after a small drop) it increased to $58 \%$ by the start of 2009 , after which it continued to increase to $62 \%$. The spillover index for bond returns also increases over the sample period. However, prior to crisis, the index fluctuated around a constant mean in the low $40 \%$. Again, we see a jump associated with the crisis, from about $42 \%$ to about $47 \%$, after which the spillover index has trended to almost $56 \%$ by the end of the sample. Thus, the behaviour of these return spillovers largely mimics the movements in the equivalent return correlations, trending upwards over time.

The spillover index plots for the variance series reveal a different pattern compared to the return series, but again have similarities across stock and bond variance. For both variance series, the value of the spillover index at the start and end of the sample is broadly similar. For stock variance, the value of the spillover is approximately $64 \%$ at the start of the sample, this falls to around 50\% in 2004 as stocks recover from the dotcom crash but then jumps to around $72 \%$ during the financial crisis before settling and remaining at around $67 \%$ until the end of the sample. For bond variance, the value of the spillover index is around $41 \%$ at the start of the sample, falls to $30 \%$ during the early 2000 s as interest rates fall in response to the dotcom crash before recovering during the rest of the 2000s, with a noticeable jump for the financial crisis. By the end of the sample, the spillover index is back to around $41 \%$. Thus, while return spillovers have increased through the sample period, variance spillovers, although exhibiting substantial fluctuation, remain relatively constant.

\section{Mean and Variance Causality and Spillovers Across Assets}

In the previous section we examine the nature of spillovers between the return and volatility of stocks and bonds separately across the four markets, i.e., the behaviour of the same asset across international markets. In this section, we consider the behaviour across assets within the same 
international market. Specifically, we examine the nature of the interrelations and spillovers between stocks and bonds within each of the four countries we examine.

Table 5 presents the Granger causality results between stock and bond returns for the four markets. ${ }^{6}$ Again, the lag length of the underlying VAR is determined by the AIC and is one for all markets. The results reveal a very clear picture, namely that causality runs from the stock market to the bond market. Across the four countries, there is significant evidence of Granger causality from stock returns to bond returns, but no corresponding causality from bond returns to stock returns, one marginal exception to that is weak (10\%) evidence for significance in the US market.

An examination of the underlying VAR reveals that in each case, the coefficient sign on the significant lagged stock return series in the bond return equation is negative. Thus, a rise in the stock return corresponds to a fall in the bond return in the subsequent month, and equally a falling stock return leads to a rising bond return. This accords with the view that stocks and bonds are competing assets and investors move between them as their risk appetite changes. This result differs from that of Tolikas (2018) who argues the any leading relation from stock to bonds returns only exists for speculative bonds and not investment grade bonds. Our results may differ as we consider sovereign bonds, whereas Tolikas only examines corporate bonds.

As with the above same asset, cross-country results, we present the spillover index in Figure 5. Across all countries, we can see that spillovers were higher during the late 1990s and early 2000s when the dotcom bubble reached its peak and then crashed. This higher spillover indicates that investors were moving between stocks and bonds over this period. Spillovers fell as stocks began to recover during the mid-2000s, but again rose during the financial crisis and remained relatively higher. ${ }^{7}$ That said, we note, the behaviour of Japanese stock and bond

\footnotetext{
${ }^{6} \mathrm{We}$ also look at spillovers between stock and bond volatility, but find little evidence of significant interaction.

7 There is no obvious event prompting the increase in UK spillovers in 2004, although there was heightened political risk at this time with the rise of the anti-European UKIP.
} 
spillovers differ from those of the remaining markets.

Given the results of the above analysis, we further examine the predictive effects between stock and bond returns. Specifically, the results in Table 3 reveal Granger causality across international stock and bond markets, while the results in Table 5 reveal Granger causality across stock and bonds within each market. Notably, Table 3 indicates causality running from the US stock market to each of the other markets, while Table 5 indicates causality from stocks to bonds. Table 6 , therefore, presents the results of a standard single equation predictive regression model for the stock and bond return in each market, regressed on a lag of the home market stock and bond return and the stock and bond return from the US. As home and US stock and bond returns respectively are likely to be highly correlated and thus encounter a multicollinearity problem, we orthogonalize home market returns. Here, we estimate a regression of home market returns on contemporaneous US market returns and obtain the residual. This residual thus captures home market information that is adjusted for (orthogonal to) US information and this approach follows that in Stehle (1977), McMillan (2016) and Lawrenz and Zorn (2018).

These results reveal an interesting role for US market information across international stock and bond markets. If we consider the bond return regressions for Germany, Japan and the UK, we note that the results in Table 5 indicate that the stock returns of these markets Granger cause the bond returns. Table 6 reveals that home market stock returns no longer affect home market bond returns (except Germany), but instead US stock returns exhibit predictive power (albeit occasionally at the 10\% significance level) for all bond market returns (including for the US). Thus, if we believe that the US stock market reflects global information, then such global stock market information dominates local stock market information in determining bond returns. Further, we can observe that global (US) bond market information affects local bond returns for Germany and Japan (and the US at the 10\% level) but not the UK. Local market 
bond returns have no significant effect. Turning to the results for stock returns, again, we can see that global (US) stock returns have a significant effect on all individual stock markets (except the US). Only for the UK is there any evidence (10\% significance level) of local stock returns affecting the home market. Global bond returns affect the local stock market for Germany, with a marginal effect for US stock returns. Thus, across all markets, US stock returns affect the stock and bond markets of all other counties, while US bonds returns affect the bond markets of Germany and Japan as well as the formers stock market.

These results expand those of Rapach et al (2013), who argue that US stock returns play a leading role in predicting local market stock returns for a range of countries. Rapach et al argue that, as the largest market, US stock returns essentially represent global information. The results here substantiate that view with US stock returns significant for German, Japanese and UK stocks. But further, we show that US stocks also predict bond market returns for the same countries and that US bond returns exhibit predictive power for German and Japanese bond returns. These results essentially confirm the dominance of global information over local market information in conditioning stock and bond returns.

\section{Causality and Spillovers in Stock and Bond Relations Across Markets}

The previous section considers how stocks and bonds interact in terms of their lead/lag relation and the nature of spillovers and causality. The correlation between stocks and bonds plays a critical role in portfolio management, as investors will move towards one particular asset given changes in their preference or perception of risk. While, we consider the general pattern in the stock and bond correlation above, here, we examine whether the correlation in one market also spillovers to other markets.

As with the mean and variance series we estimate a VAR model for the contemporaneous stock and bond return correlations and consider both the Granger causality 
test and Diebold and Yilmaz spillover index. ${ }^{8}$ Table 7 reports the Granger causality test between the stock and bond return correlations across the international markets, where the lag length in the VAR is five. The results suggest bidirectional causality across the correlations for Germany, the UK and US. In contrast, at the 5\% significance level, there is no causal relation involving Japan, although there is marginal evidence running from Japan to Germany. Where the correlation represents investors holdings of stocks and bonds, these results suggest commonality in the behaviour of investors across international markets, except for Japan.

To support the Granger causality results, Figure 6 presents the time-varying spillover index. Here, we can see that over the first part of the sample, which covers part of the dotcom crash, the spillover index rises from about $36 \%$ to a value in the low $40 \%$ s by the mid-2000s as the stock market began to recover from the crash. From this point, the index remains broadly flat, fluctuating around a relatively constant value with only a small rise to the mid-40\% range following the financial crisis period.

\section{Discussion}

The above analysis presents a series of results that can aid our understanding of the movement between the same asset across countries, different assets within a country and different assets across countries. This will improve our knowledge of market interactions, including the transmission of information across both assets and markets. This may be of use to those engaged in portfolio building, policy-making and developing models of market behaviour.

Our results reveal that correlations for the same asset across international markets rise over time, while the correlations for different assets within the same market exhibit substantial variation and both rising and falling periods and negative correlations prominent after 2000 .

\footnotetext{
${ }^{8}$ While the evidence in Figure 3 shows the contemporaneous correlation switches from positive to negative, the correlation between bond returns and lagged stock returns exhibits greater stability in terms of a consistent negative relation. Such behaviour conveys information about investor risk appetite for the alternative assets.
} 
Results also support an emerging view (see, Baur, 2010) that rising same asset correlations occur at the same time as falling cross asset correlations.

Examining causal rather than contemporaneous results, stock return and volatility spillovers largely emanate from the US and the UK towards Germany and Japan. US stock returns are particularly dominant across other market stock returns (consistent with Rapach et al, 2013). In contrast, there is greater evidence of broader interaction and bi-directional causality across the major financial centres for the bond market. Results also reveal consistent evidence that stock returns lead bond returns, providing evidence that the former exhibits predictive power for latter (this builds on the work of Tolikas, 2018, who examines corporate bonds, whereas we consider sovereign bonds). Further, movements in US stock and bond returns dominate movements in local market returns. Notably, lagged US stock returns have predictive power for both stock and bond returns across all markets (except US stock returns themselves). Examining the co-movement (correlation) between stocks and bonds across international markets, we observe a separation in behaviour. The stock and bond correlations show evidence of bi-directional causality and spillover across Germany, the UK and the US, however, movements in Japan appear unrelated. Indeed, the different behaviour of Japan is a consistent theme in the results presented here, not only differing in the correlation spillovers but also in stock return and volatility spillovers as well as the dynamics of the within market stock and bond return relation. The segmentation of Japanese financial markets has been a recurring theme in previous research and is reported by Arshanapalli and Doukas (1993), Berben and Jansen (2005) and Morana and Beltratti (2008).

These results support a particular direction of information flow across international markets and assets. For returns, we see a pattern of information flows emanating from the US to the other markets (a similar result is reported by Ehrmann et al, 2011, in respect of Euro markets). US stock returns affect US bond returns, while both affect international stock and 
bond returns. For variance (and notably bond return variance), we observe greater evidence of information flows being transmitted across the different international financial centres. For the stock and bond return correlation, we see interaction across the German, UK and US markets but with the Japanese market appearing more isolated. Regarding the strength of these spillover effects, the spillover index for stock and bond returns continually increases over the sample period. However, the same is not observed for the variance and covariance behaviour. The variance spillovers, while exhibiting notable movements around crisis periods, are broadly the same at the start and end of the sample period. The correlation spillover index rose in the early 2000s but then remained broadly flat after the mid-2000s. This implies crucial distinctions in how different aspects of information are transmitted across markets, while return spillovers appear to continually strengthen, how investors move between stocks and bonds in one market exhibits less spillover behaviour, with local information retaining its importance.

The results supporting the pre-eminent role of US stock returns in having a conditioning effect on the stock and bond returns of other markets, extends the results of Rapach et al (2013). They demonstrate that US stock returns play a key role in predicting movements of stock returns in a range of international markets, we show that this is equally true of bond markets. These results also extend the work of Tolikas (2018) who notes a predictive relation from stocks to speculative bonds within individual countries. Our results here support a predictive effect of stocks to sovereign bonds across countries.

The spillover index results further support the view that stock and bond return movements across markets continue to rise in strength. The rise in the interconnection of stock returns has been well documented (e.g., Longin and Solnik, 1995; Forbes and Rigobon, 2002; Kotkatvuori-Örnberg et al, 2013; Evans et al, 2017). In contrast, for volatility, while such spillovers exhibit a large degree of movements, their strength has generally remained constant. A similar result is reported by Tiwari et al (2018) for four different asset classes. 
Moreover, in extending these lines of research, we demonstrate the interactions across markets in the nature of the stock and bond correlation. This has previously not been examined and here we observe two distinct phenomenon. The stock and bond interaction in the markets of Germany, the UK and US are related and show evidence of bi-directional causality. This supports the view of commonality in investor decisions regarding stock and bond holdings in their portfolios across these markets. Whereas the stock and bond covariance for Japan exhibits no such commonality. Further, the strength of this interaction, measured through the spillover index, exhibits periods of both strengthening spillovers, notably over the first half of the 2000s, and weakening spillover, during the 2010s. Thus, while there is evidence of rising spillovers between the individual assets, this does not equally hold for portfolios of assets.

\section{Summary and Conclusion.}

This paper examines stock and bond returns, volatility and realised correlation for Germany, Japan, the UK and US, and investigates the nature of correlations and, through VAR models, Granger causality and time-varying spillovers. Thus, we provide a complete characterisation of mean, variance and covariance behaviour across these markets. Understanding the interaction between markets (both geographic and asset) and the transmission of information, is important for portfolio managers, policy-makers and academics.

The results suggest several key findings, some of which serve to reinforce our existing knowledge, while others add to our body of understanding. In confirmation and extension of previous work, we observe that return correlation and spillovers for the same asset across countries exhibits upward trending behaviour. The equivalent spillover results for volatility indicate a large degree of time-variation but with no given direction. We also support previous results in which US stock returns exhibit leading behaviour for other international stock returns. We further expand this result to include the behaviour of bond returns, with US bond returns 
exhibiting predictive content for German and Japanese bond returns. Moreover, bond markets show a greater degree of interaction across markets for return and volatility behaviour, whereas stock markets exhibit greater directional flows. Further, a key result is that stock returns consistently lead (predict) movements in bond returns. Our results also support an interesting pattern of behaviour in which same asset-cross market and cross asset-same market correlations move in opposite directions. This suggests a joint contagion and flight-to-safety effect.

In addition to examining stock and bond returns and volatility across and within international markets, we also look at the correlation behaviour between stocks and bond across markets. Here, two interesting results emerge. First, whereas the correlation and spillovers between stock and bond returns across different markets rise over time, the same is not true with the correlation. Cross market behaviour of the stock and bond return relation strengthens in the early 2000s and then plateaus from the late 2000s. Thus, while stock returns exhibit strengthening relations, this pattern is not replicated for variances and covariances. Second, there is evidence of interrelations and bidirectional causality between the markets of Germany, the UK and the US, whereas Japan appears distinct, a result also noted with stock return behaviour.

In sum, we provide evidence that stock returns exhibit predict content for bond returns, that US stock returns contain predictive power for all market stock and bond returns, that there is commonality in the moment of stock and bond return covariances across the markets of Germany, the UK and the US, but Japan appears less integrated and while stock returns continue to exhibit greater integration the same is not true of stock and bond market variances and covariances. The results here should allow investors to improve portfolio decision-making, policy-makers to understand (and mitigate) how information flows across markets and aid those engaged in seeking to model market and investor behaviour. 


\section{References}

Andersen, T.G. and Bollerslev, T. (1998). Answering the skeptics: Yes, standard volatility models do provide accurate forecasts. International Economic Review, 39, 885-905.

Andersen, T.G., Bollerslev, T., Diebold, F.X. and Labys, P. (2003). Modeling and forecasting realized volatility. Econometrica, 71, 579-625.

Andersson M., Krylova, E. and Vähämaa, S. (2008). Why does the correlation between stock and bond returns vary over time? Applied Financial Economics, 18, 139-151.

Arshanapalli, B. and Doukas, J. (1993). International stock market linkages: Evidence from the pre- and post-October 1987 period. Journal of Banking and Finance, 17, 193-208.

Aslanidis, N. and Christiansen, C. (2012). Smooth transition patterns in the realized stock-bond correlation. Journal of Empirical Finance, 19, 454-464.

Aslanidis, N., Christiansen, C. and Cipollini, A. (2019). Predicting bonds betas using macrofinance variables. Finance Research Letters, 29, 193-199.

Bala, D.A. and Takimoto, T. (2017). Stock markets volatility spillovers during financial crises: A DCC-MGARCH with skewed-t density approach. Borsa Istanbul Review, 17, 25-48.

Barsky, R. (1989). Why don't the prices of stocks and bonds move together? American Economic Review, 79, 1132-1145.

Baur, D. (2010). Stock-bond co-movements and cross-country linkages. International Journal of Banking, Accounting and Finance, 2, 111-129.

Baur, D and Lucey, B. (2009). Flights and contagion - an empirical analysis of stock-bond correlations. Journal of Financial Stability, 5, 339-352.

Baur, D. and Lucey, B. (2010). Is gold a hedge or a safe haven? An analysis of stocks, bonds and gold. Finance Review, 45, 217-229.

Bekaert, G., Harvey, C. and Ng, A. (2005). Market integration and contagion. Journal of Business, 78, 39-70.

Berben, R.-P. and Jansen, W.J. (2005). Comovement in international equity markets: A sectoral view. Journal of International Money and Finance, 24, 832-857.

Bollerslev, T. (1986). Generalized autoregressive conditional heteroskedasticity. Journal of Econometrics, 31, 307-327.

Campbell, J.Y. and Ammer, J. (1993). What moves the stock and bond markets? A variance decomposition for long-term asset returns. Journal of Finance, 48, 3-37.

Campbell, J.Y., Sunderam, A. and Viceira, L.M. (2017). Inflation bets or deflation hedges? The changing risks of nominal bonds. Critical Finance Review, 6, 263-301. 
Colacito. R., Engle., R. and Ghysels, E. (2011). A component model for dynamic correlations. Journal of Econometrics, 164, 45-59.

Connolly, R., Stivers, C. and Sun, L. (2005). Stock market uncertainty and the stock-bond return relation. Journal of Financial and Quantitative Analysis, 40, 161-194.

Connolly, R., Stivers, C. and Sun, L. (2007). Commonality in the time variation of stock-bond and stock-stock return comovements. Journal of Financial Markets, 10, 192-218.

Diebold, F. and Yilmaz, K. (2009). Measuring financial asset return and volatility spillovers, with application to global equity markets. Economic Journal, 119, 1-14.

Diebold, F. and Yilmaz, K. (2012). Better to give than to receive: Predictive directional measurement of volatility spillovers. International Journal of Forecasting, 28, 57-66.

Dimitriou, D., Kenourgios, D., Simos, T. (2013). Global financial crisis and emerging stock market contagion: A multivariate FIAPARCH-DCC approach. International Review of Financial Analysis, 30, 46-56.

Engle, R.F. (1982). Autoregressive conditional heteroscedasticity with estimates of the variance of United Kingdom inflation. Econometrica, 50, 987-1007.

Engle, R.F. (2002). Dynamic conditional correlation - a simple class of multivariate GARCH models. Journal of Business and Economic Statistics, 20, 339-350.

Engle, R.F., Ito, T. and Li, W.-L. (1990). Meteor showers or heat waves? Heteroskedastic intradaily volatility in the foreign exchange market. Econometrica, 58, 525-542.

Ehrmann, M., Fratzscher, M. and Rigobon, R. (2011). Stocks, bonds, money markets and exchange rates: measuring international financial transmission. Journal of Applied Econometrics, 26,948-974.

Eun, C.S. and Shin, S. (1989). International transmission of stock markets movements. Journal of Financial and Quantitative Analysis, 24, 241-256.

Evans, P. and McMillan, D.G. (2009). Financial co-movement and correlation: Evidence from 33 international stock market indices. International Journal of Banking, Accounting and Finance, 1, 215-241.

Evans, P., McMillan, D.G. and McMillan, F. (2017). Time-varying correlations and interrelations: Firm-level based sector evidence. Journal of Asset Management, 18, 209-221.

Fan, J. and Mitchell, M. (2017). Equity-bond correlation: A historical perspective. Graeme Capital Management Research Note, September, 1-3.

Forbes, K.J. and Rigobon, R. (2002). No contagion, only interdependence: Measuring stock market co-movements. Journal of Finance, 57, 2223-2261.

French, K., Schwert, G.W. and Stambaugh, R. (1987). Expected stock returns and volatility. Journal of Financial Economics, 19, 3-29. 
Granger, C. (1969). Investigating causal relations by econometric models and cross-spectral methods. Econometrica, 37, 424-438.

Gulko, L. (2002). Decoupling. Journal of Portfolio Management, 28, 59-66.

Hamao, Y., Masulis, R. and Ng, V. (1990). Correlation in price changes and volatility across international stock markets. Review of Financial Studies, 3, 281-307.

Kenourgios, D. and Dimitriou, D. (2015). Contagion of the global financial crisis and the real economy: A regional analysis. Economic Modelling, 44, 283-293.

Kim, S., Moshirian, F. and Wu, E. (2006). Evolution of international stock and bond market integration: Influence of the European Monetary Union. Journal of Banking \& Finance, 30, 1507-1534.

Koop, G., Pesaran, M.H. and Potter, S. (1996). Impulse response analysis in nonlinear multivariate models. Journal of Econometrics, 74, 119-148.

Kotkatvuori-Örnberg, J., Nikkinen, J. and Äijö, J. (2013). Stock market correlations during the financial crisis of 2008-2009: Evidence from 50 equity markets. International Review of Financial Analysis, 28, 70-78.

Lawrenz, J. and Zorn, J. (2018). Decomposing the predictive power of local and global financial valuation ratios. Quarterly Review of Economics and Finance, 70, 137-149.

Li, H. (2007). International linkages of the Chinese stock exchanges: a multivariate GARCH analysis. Applied Financial Economics, 17, 285-297.

Liu, Y.A. and Pan, M.-S. (1997). Mean and volatility spillover effects in the U.S. and PacificBasin stock markets. Multinational Finance Journal, 1, 47-62.

Longin, F. and Solnik, B. (1995). Is the correlation in international equity returns constant: 1960-1990? Journal of International Money and Finance, 14, 3-26.

McAleer, M. and Medeiros, M.C. (2008). Realized volatility: A review. Econometric Reviews, $27,10-45$.

McMillan, D.G. (2016). Stock return predictability and market integration: The role of global and local information', Cogent Economics and Finance, 4, 1-18 (On-Line).

McMillan, D.G. (2019). Cross-asset relations, correlations and economic implications. Global Finance Journal, 41, 60-78.

McMillan, D.G., Ruiz, I and Speight, A. (2010). Common volatility, spillovers and timevarying correlations in three Euro rates. European Journal of Finance, 16, 753-767.

McMillan, D.G., Speight, A. and ap Gwilym, O. (2000). Forecasting UK stock market volatility. Applied Financial Economics, 10, 435-448. 
Mensi, W., Hammoudeh, S. Nguyen, D.K. and Kang, S.H. (2016). Global financial crisis and spillover effects among the U.S. and BRICS stock markets. International Review of Economics \& Finance, 42, 257-276.

Morana, C. and Beltratti, A. (2008). Comovements in international stock markets. Journal of International Financial Markets, Institutions and Money, 18, 31-45.

Nakajima, T. (2019). Test for volatility spillover effects in Japan's oil futures markets by a realized variance approach. Studies in Economics and Finance, 36, 224-239.

Pagan, A, and Schwert, G.W. (1990). Alternative models for conditional stock volatility. Journal of Econometrics, 45, 267-290.

Pesaran, M.H. and Shin, Y. (1998). Generalized impulse response analysis in linear multivariate models. Economics Letters, 58, 17-29.

Rankin, E. and Shah Idil, M. (2014). A century of stock-bond correlations. Reserve Bank of Australia Bulletin, September, 67-74.

Rapach, D., Strauss, J. and Zhou, G. (2013). International stock return predictability: What is the role of the United States? Journal of Finance, 68, 1633-1662.

Schwert, G.W. (1989). Why does stock market volatility change over time? Journal of Finance, $44,1115-1153$.

Shiller, R.J. and Beltratti, A.E. (1992). Stock prices and bond yields: Can their comovements be explained in terms of present value models? Journal of Monetary Economics, 30, 25-46.

Sims, C.A. (1980). Macroeconomics and Reality. Econometrica, 48, 1-48.

Stehle, R. (1977). An empirical test of the alternative hypotheses of national and international pricing of risky assets. Journal of Finance, 32, 493-502.

Tiwari, A., Cunado, J., Gupta, R. and Wohar, M.E. (2018). Volatility spillovers across global asset classes: Evidence from time and frequency domains. Quarterly Review of Economics and Finance, 70, 194-202.

Tolikas, K. (2018). The lead-lag relation between the stock and the bond markets. European Journal of Finance, 24, 849-866.

Viceira, L.M. (2012). Bond risk, bond return volatility, and the term structure of interest rates. International Journal of Forecasting, 28, 97-117. 
Table 1. Summary Statistics for Returns and Volatility

\begin{tabular}{|l|l|l|l|l|l|l|}
\hline & Mean & Std Dev & Min & Max & Skew & Kurt \\
\hline & \multicolumn{6}{|c|}{ Bonds Returns } \\
\hline DE & 0.133 & 1.732 & -8.110 & 5.827 & -0.407 & 4.435 \\
\hline JP & 0.155 & 1.637 & -9.095 & 5.970 & -0.916 & 8.273 \\
\hline UK & 0.209 & 2.342 & -9.449 & 7.769 & -0.313 & 4.719 \\
\hline US & 0.095 & 2.375 & -9.198 & 10.933 & 0.153 & 4.595 \\
\hline \multicolumn{7}{|c|}{ Stock Returns } \\
\hline DE & 0.539 & 5.260 & -24.613 & 15.173 & -0.940 & 5.843 \\
\hline JP & 0.327 & 5.288 & -22.775 & 17.680 & -0.422 & 4.495 \\
\hline UK & 0.636 & 4.503 & -29.938 & 13.618 & -1.196 & 8.163 \\
\hline US & 0.725 & 4.299 & -23.545 & 12.277 & -0.915 & 6.205 \\
\hline \multicolumn{7}{|c|}{ Bond Volatility } \\
\hline DE & 0.024 & 0.022 & 0.001 & 0.197 & 2.756 & 14.964 \\
\hline JP & 0.021 & 0.033 & 0.000 & 0.109 & 4.086 & 22.875 \\
\hline UK & 0.050 & 0.065 & 0.005 & 0.639 & 4.368 & 28.158 \\
\hline US & 0.055 & 0.055 & 0.006 & 0.511 & 3.394 & 19.618 \\
\hline \multicolumn{7}{|l|}{ Stock Volatility } \\
\hline DE & 0.266 & 0.417 & 0.016 & 6.308 & 7.777 & 99.603 \\
\hline JP & 0.307 & 0.480 & 0.008 & 7.439 & 8.779 & 116.369 \\
\hline UK & 0.220 & 0.365 & 0.016 & 4.695 & 7.646 & 81.073 \\
\hline US & 0.249 & 0.505 & 0.016 & 6.920 & 8.724 & 98.807 \\
\hline No
\end{tabular}

Notes: Summary statistics are for German (DE), Japanese (JP), UK and US monthly bond and stock returns and volatility. Volatility is calculated from aggregated daily squared returns (realised volatility). 
Table 2. Correlation between the Same Asset-Cross Market Correlation and the Cross Asset-Same Market Correlation

\begin{tabular}{|c|c|c|c|c|c|c|}
\hline \multirow{2}{*}{$\begin{array}{l}\text { Cross- } \\
\text { Asset Corr }\end{array}$} & \multicolumn{6}{|c|}{ Same Asset Correlation } \\
\hline & DEJP & DEUK & JPUK & DEUS & JPUS & UKUS \\
\hline & \multicolumn{6}{|c|}{ Bonds } \\
\hline $\mathrm{DE}$ & 0.015 & -0.629 & -0.135 & -0.575 & -0.029 & -0.404 \\
\hline JP & 0.067 & -0.465 & -0.091 & -0.416 & -0.046 & -0.347 \\
\hline UK & -0.017 & -0.627 & -0.151 & -0.604 & -0.069 & -0.410 \\
\hline \multirow[t]{2}{*}{ US } & 0.026 & -0.625 & -0.153 & -0.613 & -0.069 & -0.423 \\
\hline & \multicolumn{6}{|c|}{ Stocks } \\
\hline $\mathrm{DE}$ & 0.013 & -0.541 & -0.166 & -0.647 & -0.072 & -0.458 \\
\hline $\mathrm{JP}$ & -0.020 & -0.489 & -0.044 & -0.405 & 0.021 & -0.226 \\
\hline UK & -0.022 & -0.597 & -0.171 & -0.632 & -0.080 & -0.434 \\
\hline US & -0.028 & -0.608 & -0.190 & -0.650 & -0.068 & -0.410 \\
\hline \multicolumn{7}{|c|}{$\begin{array}{l}\text { Notes: Entries are the correlation coefficient between the stock and bond return correlation } \\
\text { for each individual country, given in the first column, with the same asset correlation across } \\
\text { two countries, given in the second row. As an example, in the first cell } 0.015 \text { is the correlation } \\
\text { coefficient between the correlation between German stock and bond returns with the } \\
\text { correlation between German and Japanese bond returns. }\end{array}$} \\
\hline
\end{tabular}


Table 3. Granger Causality Results for Stocks Returns and Volatility Across Countries

\begin{tabular}{|l|l|l|}
\hline & Return & Volatility \\
\hline Direction & F-Test (p-value) & F-Test (p-value) \\
\hline $\mathrm{DE} \rightarrow \mathrm{JP}$ & $0.22(0.81)$ & $0.32(0.73)$ \\
\hline $\mathrm{JP} \rightarrow \mathrm{DE}$ & $0.97(0.38)$ & $1.31(0.27)$ \\
\hline $\mathrm{DE} \rightarrow \mathrm{UK}$ & $0.25(0.78)$ & $1.44(0.24)$ \\
\hline $\mathrm{UK} \rightarrow \mathrm{DE}$ & $4.38(0.01)$ & $24.69(0.00)$ \\
\hline $\mathrm{DE} \rightarrow \mathrm{US}$ & $0.33(0.72)$ & $0.93(0.40)$ \\
\hline $\mathrm{US} \rightarrow \mathrm{DE}$ & $4.00(0.02)$ & $21.46(0.00)$ \\
\hline $\mathrm{JP} \rightarrow \mathrm{UK}$ & $2.59(0.08)$ & $2.75(0.07)$ \\
\hline $\mathrm{UK} \rightarrow \mathrm{JP}$ & $2.60(0.08)$ & $7.22(0.00)$ \\
\hline $\mathrm{JP} \rightarrow \mathrm{US}$ & $0.32(0.73)$ & $0.19(0.83)$ \\
\hline $\mathrm{US} \rightarrow \mathrm{JP}$ & $3.24(0.04)$ & $5.35(0.01)$ \\
\hline $\mathrm{UK} \rightarrow \mathrm{US}$ & $0.20(0.82)$ & $3.04(0.05)$ \\
\hline $\mathrm{US} \rightarrow \mathrm{UK}$ & $3.69(0.03)$ & $0.05(0.95)$ \\
\hline
\end{tabular}

Notes: Entries are the $F$-test (and associated $p$-value) for the null hypothesis of no Granger causality in a VAR whose lag length is determined by the AIC. 
Table 4. Granger Causality Results for Bond Returns and Volatility Across Countries

\begin{tabular}{|l|l|l|}
\hline & Return & Volatility \\
\hline Direction & F-Test (p-value) & F-Test (p-value) \\
\hline $\mathrm{DE} \rightarrow \mathrm{JP}$ & $8.53(0.00)$ & $1.94(0.04)$ \\
\hline $\mathrm{JP} \rightarrow \mathrm{DE}$ & $4.40(0.04)$ & $3.32(0.00)$ \\
\hline $\mathrm{DE} \rightarrow \mathrm{UK}$ & $0.22(0.64)$ & $3.43(0.00)$ \\
\hline $\mathrm{UK} \rightarrow \mathrm{DE}$ & $3.15(0.08)$ & $1.27(0.25)$ \\
\hline $\mathrm{DE} \rightarrow \mathrm{US}$ & $1.34(0.25)$ & $1.47(0.15)$ \\
\hline $\mathrm{US} \rightarrow \mathrm{DE}$ & $15.80(0.00)$ & $0.62(0.78)$ \\
\hline $\mathrm{JP} \rightarrow \mathrm{UK}$ & $4.80(0.03)$ & $3.02(0.00)$ \\
\hline $\mathrm{UK} \rightarrow \mathrm{JP}$ & $6.34(0.01)$ & $7.25(0.00)$ \\
\hline $\mathrm{JP} \rightarrow \mathrm{US}$ & $0.02(0.88)$ & $3.11(0.00)$ \\
\hline $\mathrm{US} \rightarrow \mathrm{JP}$ & $7.71(0.01)$ & $2.03(0.04)$ \\
\hline $\mathrm{UK} \rightarrow \mathrm{US}$ & $1.31(0.25)$ & $4.07(0.00)$ \\
\hline $\mathrm{US} \rightarrow \mathrm{UK}$ & $1.67(0.20)$ & $3.65(0.00)$ \\
\hline
\end{tabular}

Notes: Entries are the $F$-test (and associated $p$-value) for the null hypothesis of no Granger causality in a VAR whose lag length is determined by the AIC. 
Table 5. Granger Causality for Stock and Bond Returns Within a Country

\begin{tabular}{|l|l|l|}
\hline & $\mathrm{S} \rightarrow \mathrm{B}$ & $\mathrm{B} \rightarrow \mathrm{S}$ \\
\hline & F-Stat $(\mathrm{p}$-value $)$ & F-Stat $(\mathrm{p}$-value $)$ \\
\hline Germany & $18.02(0.00)$ & $2.16(0.14)$ \\
\hline Japan & $7.47(0.01)$ & $0.75(0.39)$ \\
\hline UK & $4.31(0.04)$ & $0.55(0.46)$ \\
\hline US & $12.72(0.00)$ & $3.47(0.06)$ \\
\hline
\end{tabular}

Notes: Entries are the $F$-test (and associated $p$-value) for the null hypothesis of no Granger causality in a VAR whose lag length is determined by the AIC.

Table 6. Predictive Regression Results for Stock and Bond Returns

\begin{tabular}{|l|l|l|l|l|}
\hline & Home Stocks & Home Bonds & US Stocks & US Bonds \\
\hline DE - Stocks & $0.003(0.04)$ & $0.046(0.23)$ & $0.191(2.95)$ & $0.205(2.40)$ \\
\hline DE - Bonds & $-0.059(-2.62)$ & $-0.069(1.08)$ & $-0.042(-1.94)$ & $0.117(2.62)$ \\
\hline JP - Stocks & $0.058(0.74)$ & $0.129(0.82)$ & $0.188(3.25)$ & $0.075(0.72)$ \\
\hline JP - Bonds & $-0.026(-1.57)$ & $0.049(0.67)$ & $-0.039(-1.69)$ & $0.112(3.21)$ \\
\hline UK- Stocks & $-0.139(-1.90)$ & $0.061(0.54)$ & $0.204(2.22)$ & $0.097(1.17)$ \\
\hline UK - Bonds & $0.026(0.68)$ & $-0.023(-0.34)$ & $-0.080(-2.95)$ & $0.067(1.37)$ \\
\hline US - Stocks & - & - & $0.068(1.06)$ & $0.157(1.86)$ \\
\hline US - Bonds & - & - & $-0.089(-2.71)$ & $0.082(1.89)$ \\
\hline
\end{tabular}

Notes: Entries are the coefficient values (and Newey-West $t$-values) of the predictive regression of each countries stock and bond return regressed on a lag of their own returns and a lag of the US returns (the home and US returns are orthogonalised prior to estimating the above model). 
Table 7. Granger Causality Results for Stock-Bond Return Correlation Across Countries

\begin{tabular}{|l|l|}
\hline & F-Stat $(\mathrm{p}$-value) \\
\hline Germany $\rightarrow$ Japan & $1.20(0.31)$ \\
\hline Japan $\rightarrow$ Germany & $2.18(0.06)$ \\
\hline Germany $\rightarrow$ UK & $2.35(0.04)$ \\
\hline UK $\rightarrow$ Germany & $5.41(0.00)$ \\
\hline Germany $\rightarrow$ US & $4.24(0.00)$ \\
\hline US $\rightarrow$ Germany & $3.48(0.00)$ \\
\hline Japan $\rightarrow$ UK & $0.81(0.54)$ \\
\hline UK $\rightarrow$ Japan & $0.23(0.95)$ \\
\hline Japan $\rightarrow$ US & $1.05(0.39)$ \\
\hline US $\rightarrow$ Japan & $0.56(0.73)$ \\
\hline UK $\rightarrow$ US & $4.22(0.00)$ \\
\hline US $\rightarrow$ UK & $3.55(0.00)$ \\
\hline $\begin{array}{l}\text { Notes: Entries are the } F \text {-test (and associated } p \text {-value) for the null hypothesis of no Granger } \\
\text { causality in a VAR whose lag length is determined by the AIC. }\end{array}$ \\
\hline
\end{tabular}


Figure 1. Return and Volatility Time Series Plots
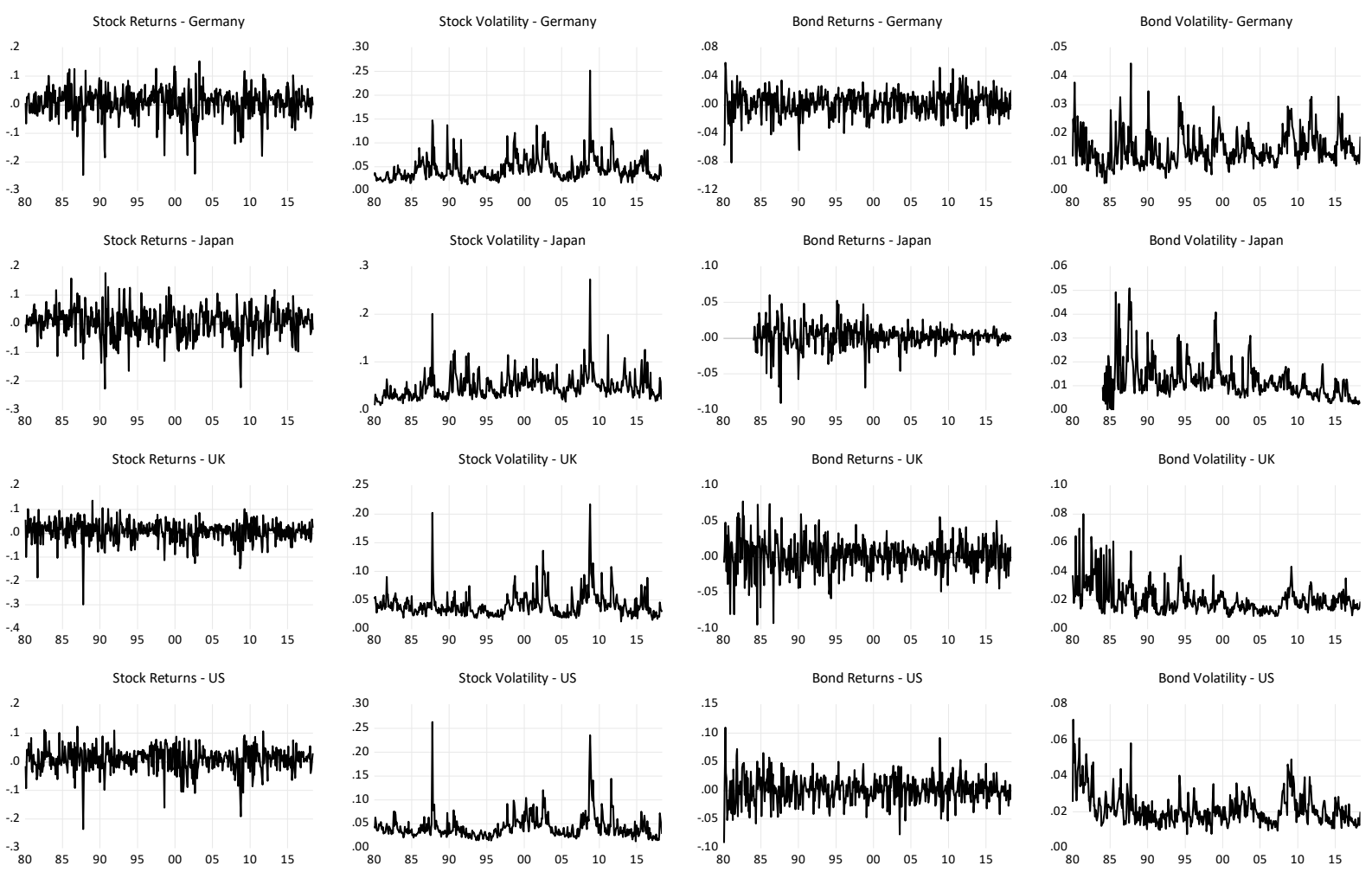
Figure 2. Bond-Bond and Stock-Stock Correlations across Markets

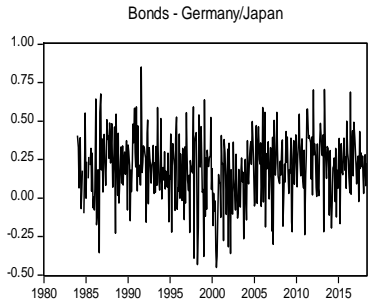

Bonds - Japan/US

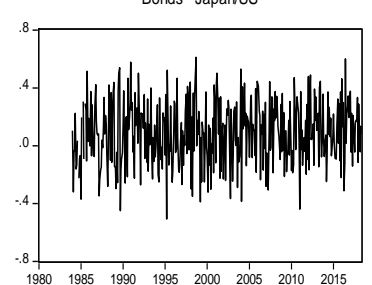

Stocks - Japan/UK

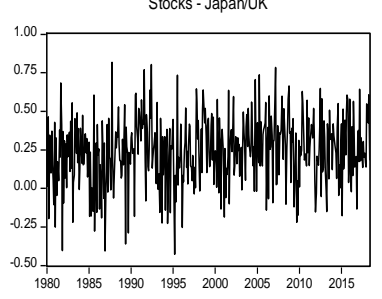

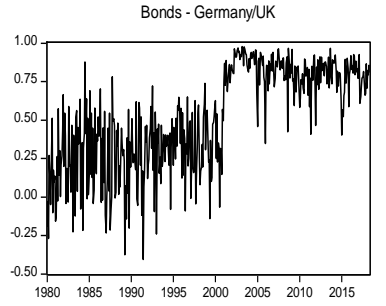

Bonds - UK/US

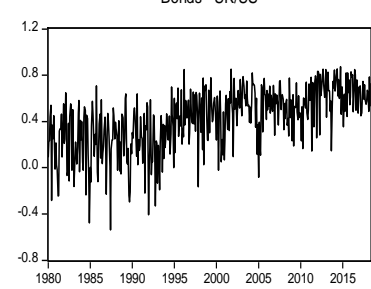

Stocks - Germany/US

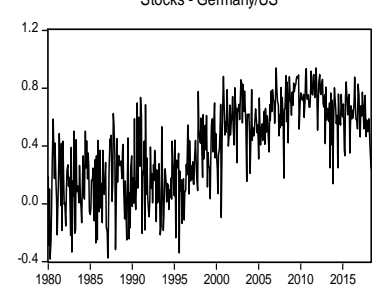

Bonds - Japan/UK

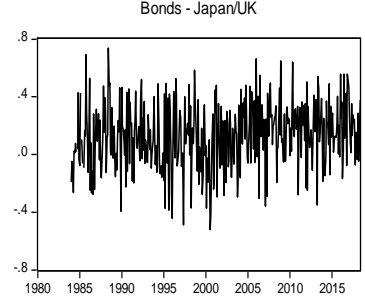

Stocks - Germany/Japan

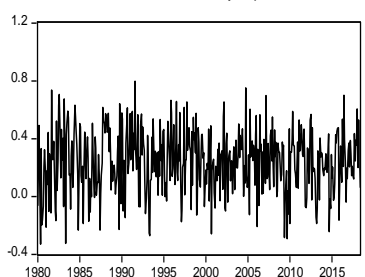

Stocks - Japan/US

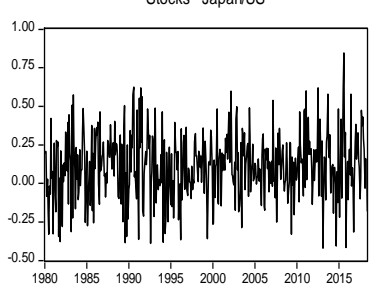

Bonds - Germany/US

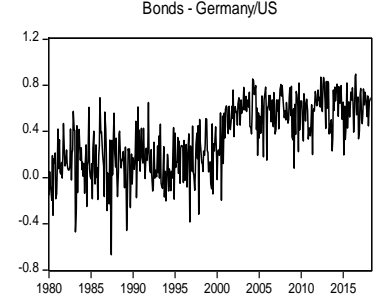

Stocks - Germany/UK

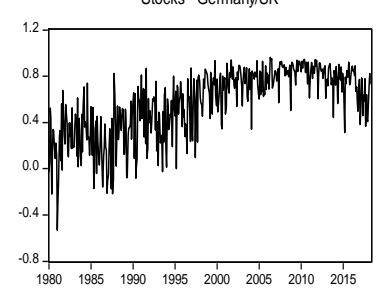

Stocks - UK/US

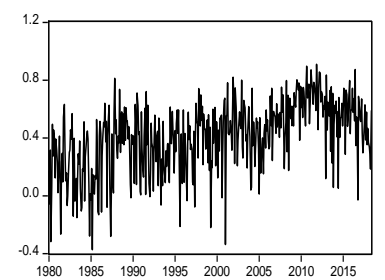


Figure 3. Stock and Bond Correlation
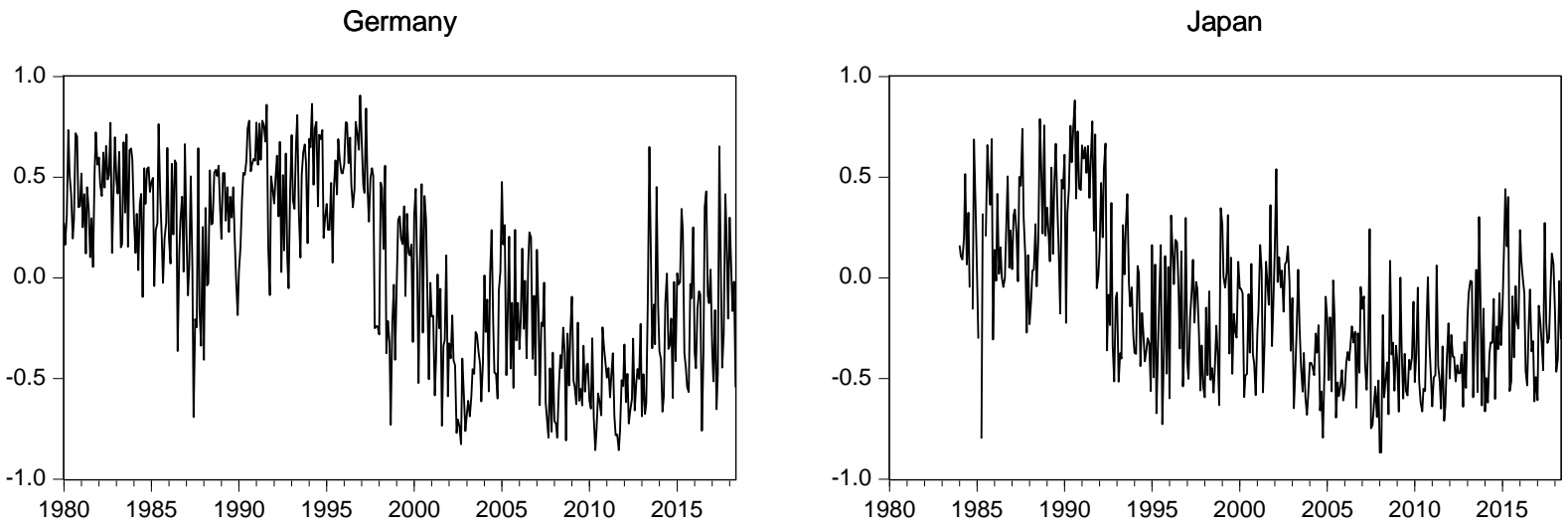

UK

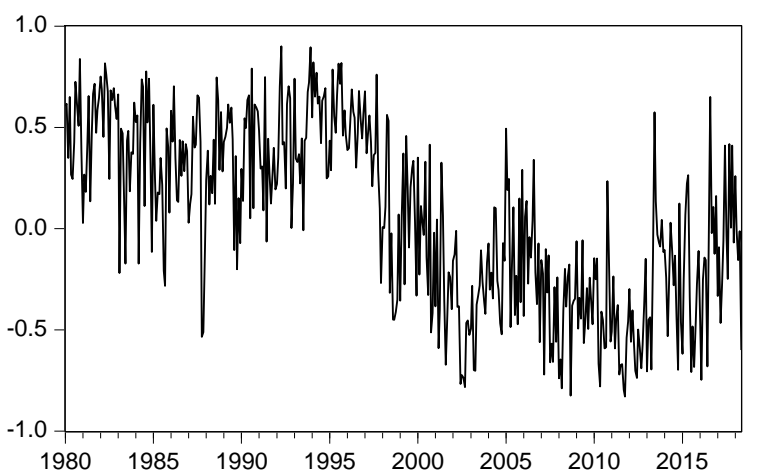

US

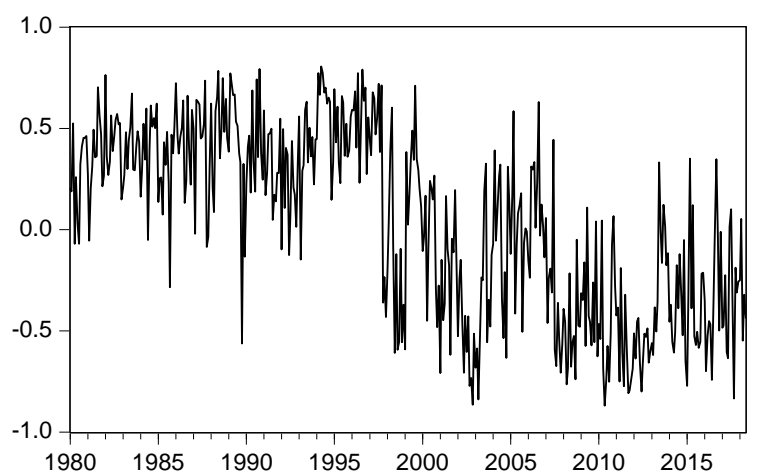


Figure 4. Stock and Bond Market Spillover Index

Stock Return Spillover Index

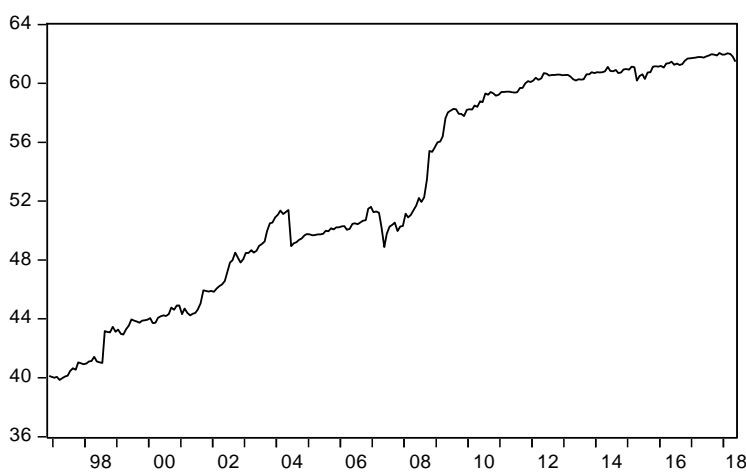

Bond Return Spillover Index

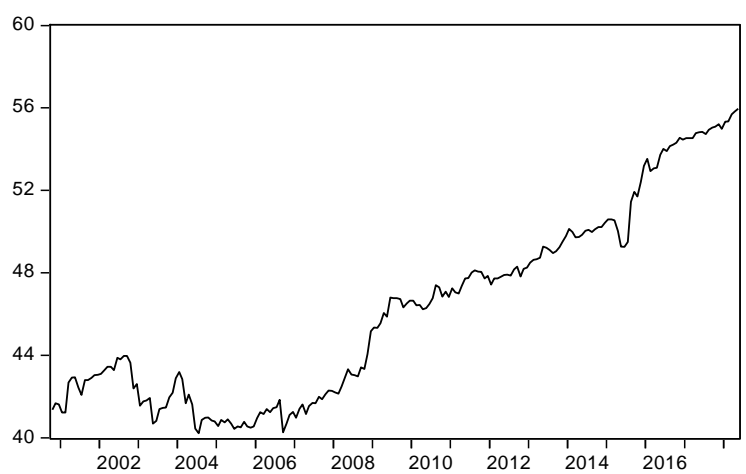

Stock Volatility Spillover Index

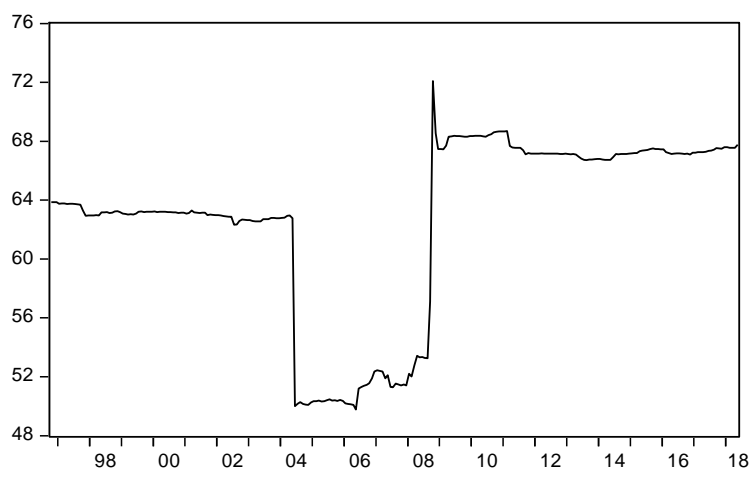

Bond Volatility Spillover Index

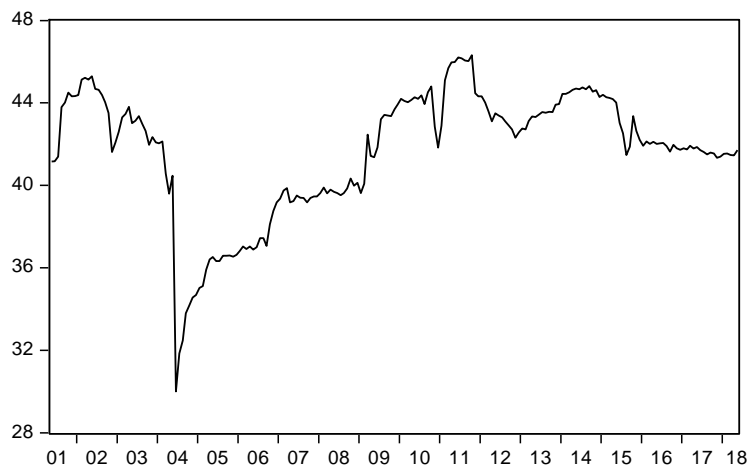


Figure 5. Bond and Stock Return Spillover Index
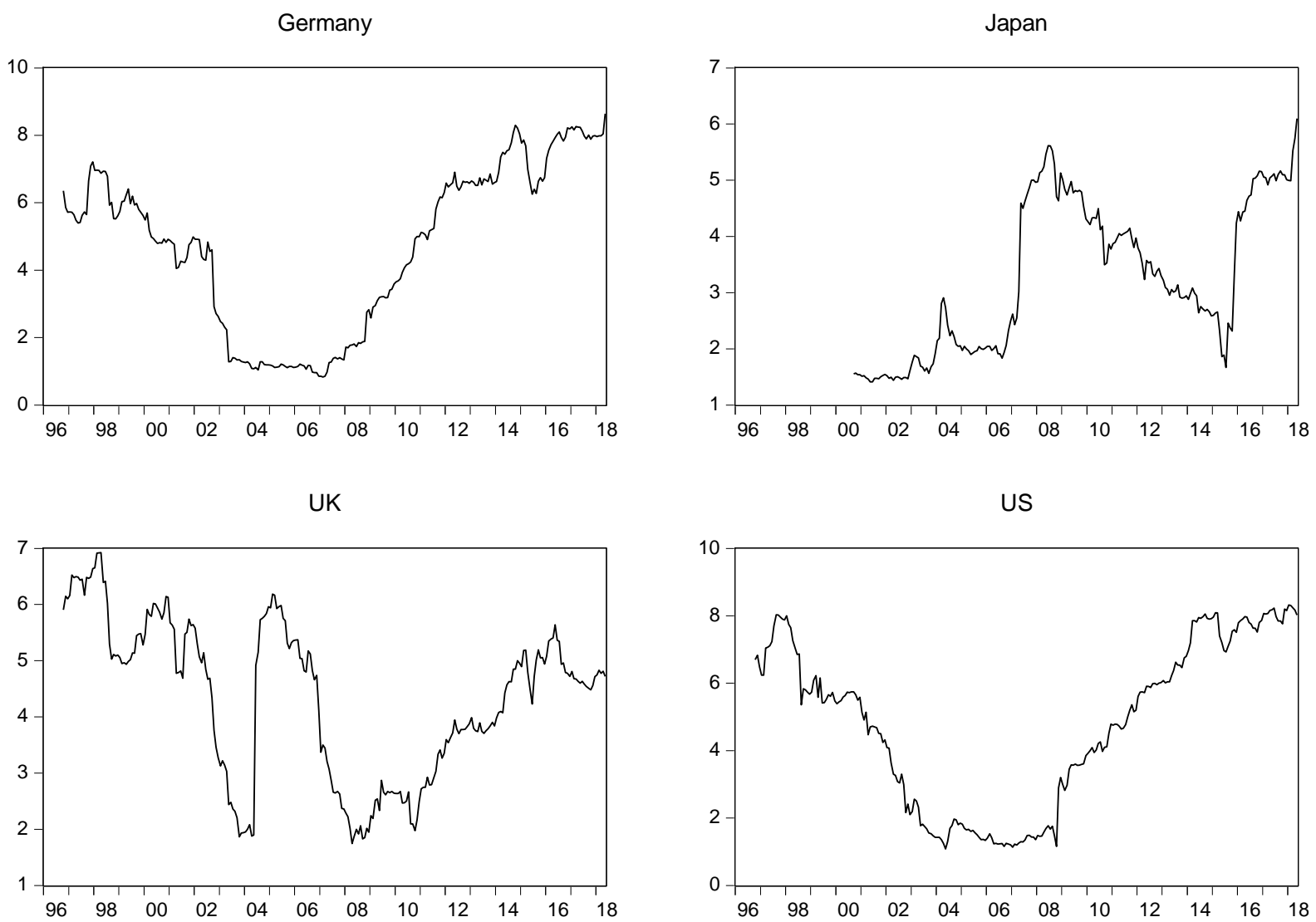
Figure 6. Correlation Spillover Index

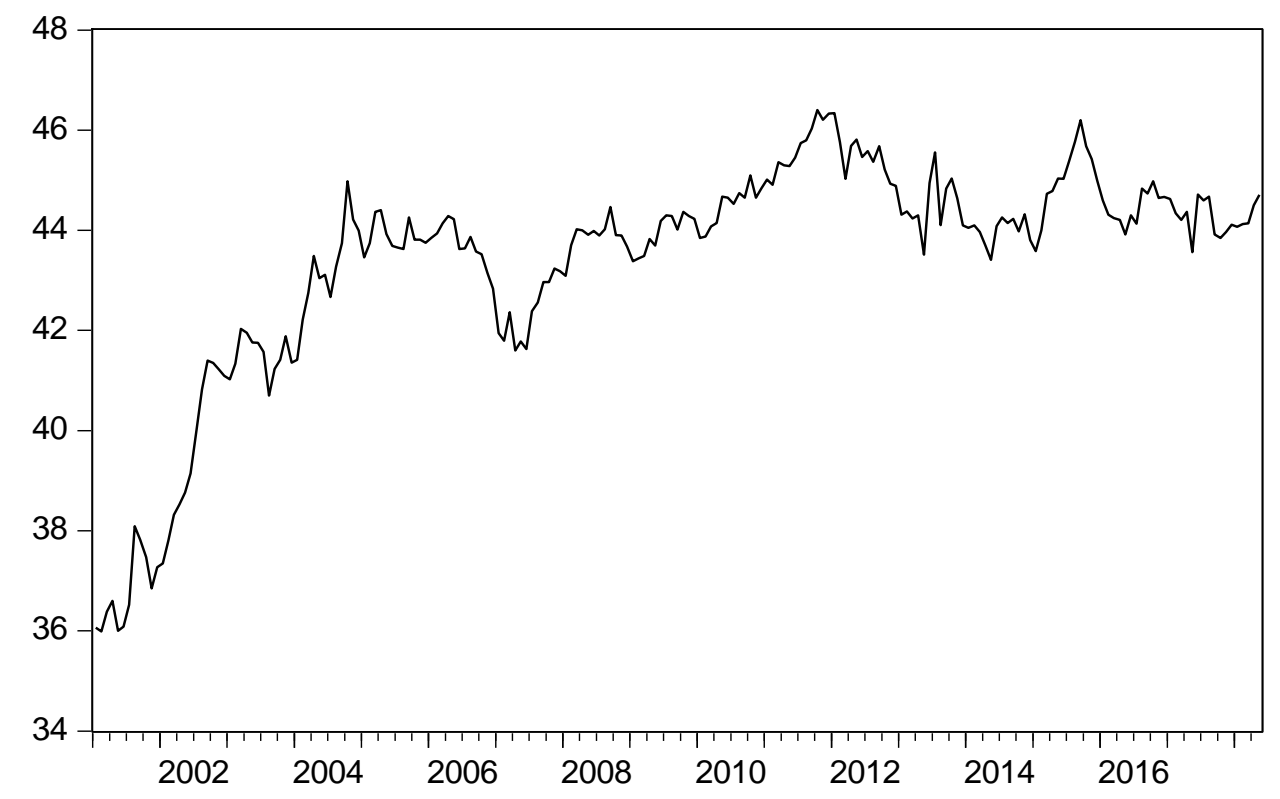

